Check for updates

Cite this: Chem. Commun., 2021, 57,11956

Received 24th August 2021, Accepted 15th October 2021

DOI: $10.1039 / \mathrm{d} 1 \mathrm{cc} 04716 \mathrm{~g}$

rsc.li/chemcomm

\section{Ball milling - a new concept for predicting degradation profiles in active pharmaceutical ingredients $\uparrow$}

\author{
Reinhard P. Kaiser, ${ }^{a}$ Everaldo F. Krake, (DD ${ }^{b}$ Laura Backer, ${ }^{c}$ Jonas Urlaub, ${ }^{c}$ \\ Wolfgang Baumann, (D ${ }^{b}$ Norbert Handler, ${ }^{d}$ Helmut Buschmann, ${ }^{d}$ \\ Torsten Beweries, (D) ${ }^{b}$ Ulrike Holzgrabe (D) *c and Carsten Bolm (D) ${ }^{a}$
}

\begin{abstract}
A method for forced oxidative mechanochemical degradation of active pharmaceutical ingredients (APIs) using clopidogrel hydrogensulfate as a model compound is presented. Considerable and selective formation of degradants occurs already after very short reaction times of less than 15 minutes and the nature of the products is strongly dependent on the used oxidant.
\end{abstract}

Virtually all pharmaceutical formulations are multicomponent and multiphase systems in (un)stable matrices. Upon approval application at regulatory authorities (such as the FDA and EMA) stability data must be submitted. However, there is a significant lack of predictive tools for solid-state characteristics, especially with respect to solid-state stability and degradation. ${ }^{1}$ Also, kinetics and decomposition products of solid-state degradation processes are unique for each compound, making the development of stability models very time-consuming and costly. Available prediction methods in aqueous environments result in high failure rates as non-relevant degradants may be formed resulting in high development risk for the manufacturer of new drugs and for the patient.

Clopidogrel hydrogensulfate (Clp) is a well-established drug substance showing direct inhibition of adenosine diphosphate (ADP) binding to its receptor and thus the ADP-mediated activation of the glycoprotein GPIIb/IIIa complex. ${ }^{2}$ It acts as platelet aggregation inhibitor and is indicated for the treatment and management of heart attack and stroke, coronary and artery occlusion. The active pharmaceutical ingredient (API) is

\footnotetext{
${ }^{a}$ RWTH Aachen University, Institute of Organic Chemistry, Landoltweg 1, 52074 Aachen, Germany.E-mail: carsten.Bolm@oc.rwth-aachen.de

${ }^{b}$ Leibniz-Institut für Katalyse e.V., Albert-Einstein-Str. 29a, 18059 Rostock, Germany. E-mail: torsten.beweries@catalysis.de

${ }^{c}$ Institut für Pharmazie und Lebensmittelchemie, Am Hubland, 97074 Würzburg, Germany. E-mail: ulrike.holzgrabe@uni-wuerzburg.de

${ }^{d}$ RD\&C Research, Development \& Consulting GmbH, Neuwaldegger Strasse 35/2/3, 1170 Vienna, Austria

$\dagger$ Electronic supplementary information (ESI) available. See DOI: 10.1039/ d1 1 c $04716 \mathrm{~g}$
}

marketed in various oral drug formulations mainly as tablets with immediate release but also modified release formulations. The characteristics of Clp are summarised in Fig. 1a.

Currently, the European Pharmacopoeia (Ph. Eur.) reveals the four impurities for Clp (impurity A-D, Fig. 1b), however, no oxidative impurity is specified. ${ }^{3,4}$ To evaluate potential oxidative degradation products, usually forced degradation conditions in solution (i.e. with aqueous $\mathrm{H}_{2} \mathrm{O}_{2}$ ) are applied. Although stability indicating analytical methods were described, none included complete forced degradation studies elucidating all chemical structures of (potential) degradation products. ${ }^{5,6}$ For example, Singh and co-workers characterised several degradation products under solid-state stress conditions applying accelerated $\mathrm{ICH}^{7}$ conditions $\left(40{ }^{\circ} \mathrm{C} / 75 \%\right.$ relative humidity) and solid stressors such as oxalic acid and $\mathrm{Na}_{2} \mathrm{CO}_{3}$ over a period of 1 or 3 months. ${ }^{8}$ These studies identified several structures including oxidative and

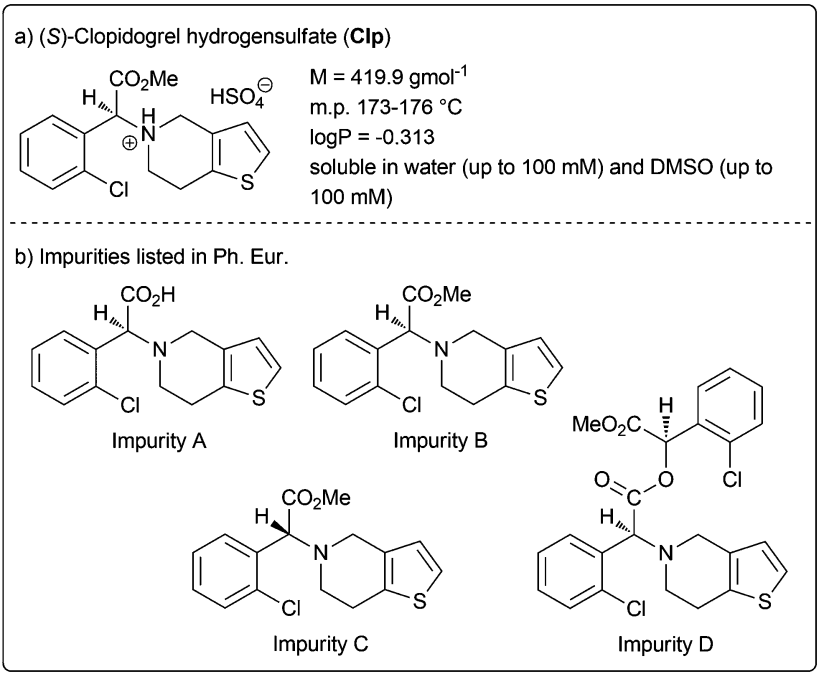

Fig. 1 Clopidogrel hydrogensulfate (Clp) and impurities listed in the European Pharmacopoeia (Ph. Eur.). 
hydrolytic degradants, although no explicit oxidative conditions were applied.

With the goal to overcome apparent deficits of current forced degradation studies (long incubation time, not all stressors available as solids, inefficient reactions, complex and misleading degradation profiles) we started looking for an innovative, fast, and reproducible method to mimic solid-state degradation of APIs like Clp. In particular we became interested in producing oxidative degradants avoiding commonly used solutions like $\mathrm{H}_{2} \mathrm{O}_{2}$, which often result in complex degradation profiles or even irrelevant products due to harsh conditions, undesired reaction pathways and strong solvent effects. After in-depth screening of suitable methods, we finally identified mechanochemistry as a highly versatile, efficient, and reproducible preparative application for our purposes.

Mechanochemistry has proven relevant in various field of research, ${ }^{9}$ including organic synthesis ${ }^{10}$ and pharmaceutical, ${ }^{11}$ medicinal, ${ }^{12}$ and agrochemical sciences. ${ }^{13}$ By applying mechanochemical techniques, existing reaction pathways could be affected leading to higher efficiencies compared to established protocols. For example, catalyst loadings could be reduced ${ }^{14}$ and product distributions be altered. ${ }^{10,15}$ Surprisingly, despite the success of mechanochemistry, its applications in pharmaceutical sciences have been limited mostly to the study of polymorphism of solid drugs and to the formation of co-crystals containing APIs. ${ }^{16}$ However, the existing knowledge on mechanosyntheses of organic molecules ${ }^{17}$ was foreseen as an ideal platform for inducing solid-state oxidative transformations of functional groups present in APIs. To best of our knowledge, although ball milling has been proven to be predictive for degradation processes of a drug, ${ }^{18}$ a systematic mechanochemical approach has not been applied to date to overcome the above-mentioned shortcomings of forced degradation studies.

The quality of drugs is controlled by the Ph. Eur. by means of a test for related substances, which can limit synthesis by- and starting products as well as degradation products. The Ph. Eur. methods in the Clp monograph ${ }^{3}$ make use of an ion-pair RP-HPLC method including Na-pentanesulfonate and phosphoric acid as mobile phase additives, which is not MS compatible for structure elucidation of unknown mechanochemically-generated degradation products. In contrast, both Singh and co-workers ${ }^{8}$ and Mashelkar and Renapurkar ${ }^{6}$ reported similar stability-indicating RP-HPLC methods for the elucidation of degradation products occurring on various stressing conditions. Those methods were taken as a starting point for development, optimisation and validation of a method, which is able to separate the Clp degradation impurities produced by ball-milling. The separation was carried out using a C8 double-end capped column with a carbon load of $7 \%$ and a gradient elution with water and $\mathrm{MeCN} / \mathrm{HCOOH}(0.1 \%)$. The method is sufficiently sensitive, accurate and precise (see ESI $\dagger$ for details) for degradation product profiling. Since especially the oxidant $\mathrm{KNO}_{3}$ (but also with $\mathrm{KMnO}_{4}$ ) produced a tailing of the main degradation product (Fig. S2, ESI $\dagger$ ) maybe by continuously forming and destroying a complex with this product, the mobile phase was slightly modified and $\mathrm{HCOOH}$ was replaced by $0.1 \%$ trifluoroacetic acid, which increased the efficiency likely by forming a more stable ion pair. Even though the retention time of the peaks was increased, the elution order and separation were similar (Fig. S2-S4, ESI $\dagger$ ), but no additional peaks were observed by this orthogonal approach even though the non-tailing of the degradant opens "space" for peaks of related substances.

Clp shows polymorphism. Six different polymorphic forms and an amorphous form of the drug have been identified. ${ }^{19,20}$ Depending on the modification, different degradation products can be formed. ${ }^{8}$ In order to clarify in which form the API is present, a PXRD pattern was recorded (Fig. S1, ESI $\dagger$ ). The comparison with literature patterns, ${ }^{19}$ showed that Clp used is present in polymorphic form I.

For the evaluation of the mechanochemical degradation under oxidative conditions, we have used three oxidants, $\mathrm{KMnO}_{4}, \mathrm{KNO}_{3}$, as well as $\mathrm{KHSO}_{5} \cdot 0.5 \mathrm{KHSO}_{4} \cdot 0.5 \mathrm{~K}_{2} \mathrm{SO}_{4}$ (oxone ${ }^{\circledR}$ ). Mixtures of these compounds and Clp were mixed with a defined amount of inert $\mathrm{SiO}_{2}$ and stressed at a frequency of $30 \mathrm{~Hz}$ in $\mathrm{ZrO}_{2}$ jars and balls using a mixer ball mill for $t=1-$ 15 min. Milling times of 15 minutes were sufficient for conversion of $30-40 \%$ of Clp (determined by ${ }^{1} \mathrm{H}$ NMR), depending on the oxidant used. The physical changes observed during solidstate oxidative degradation are shown in Fig. 2.

Reducing the milling frequency to values below $20 \mathrm{~Hz}$ gave no conversion of Clp. Longer reaction times resulted in higher degradation of the API but were not necessary for the identification of characteristic degradation profiles. As an example, the LC-MS analysis of a reaction of Clp with $\mathrm{KNO}_{3}$ for $120 \mathrm{~min}$ is shown in Fig. S9 (ESI $\dagger$ ).

All samples remained solid, albeit with pronounced colour differences: whereas samples treated with $\mathrm{KMnO}_{4}$ showed an intense brown colour (due to formation of $\mathrm{MnO}_{2}$ ) after ball milling, mixtures obtained after milling with $\mathrm{KNO}_{3}$ and oxone were pale yellow to yellow, indicating the formation of degradants that possess chromophoric groups. Workup of these samples was done by washing with $\mathrm{MeCN}$, followed by filtration and concentration to dryness in vacuum. Thus obtained oily residues were free of residual oxidant and subsequently analysed by HPLC-MS ${ }^{21}$ using the described method (Fig. S8-S12, ESI $\dagger$ ), as well as NMR and ATR-IR spectroscopy. Especially ${ }^{1} \mathrm{H}$ NMR analysis is well suited as structural changes affecting the heterocycle moieties of Clp should be readily detectable at lower field (Fig. 3).

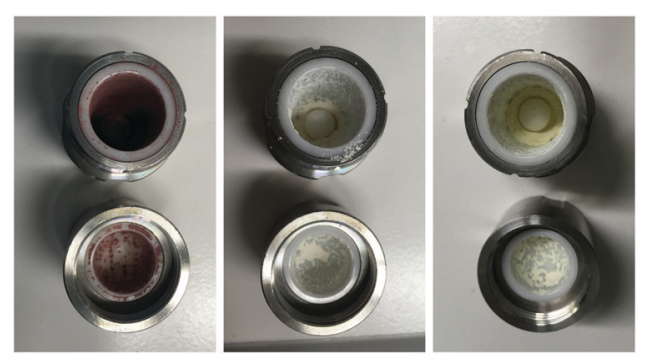

Fig. 2 Photographs of ball-milled Clp samples using $\mathrm{KMnO}_{4}$ (left), oxone ${ }^{\mathbb{R}}$ (centre), and $\mathrm{KNO}_{3}$ (right) as the oxidant after $t=15 \mathrm{~min}$. 


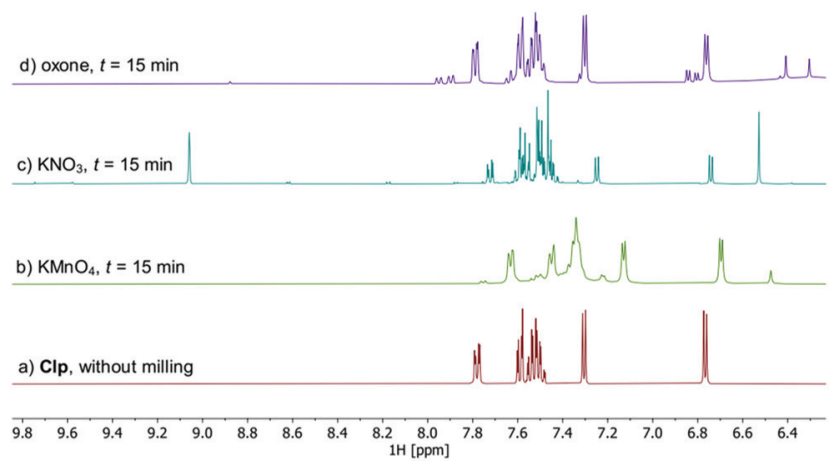

Fig. 3 Comparison of the low-field region of ${ }^{1} \mathrm{H}$ NMR spectra recorded after ball milling of $\mathrm{Clp}$ with $\mathrm{SiO}_{2}$ and one equivalent of oxidant for $t=15$ min $\left(\mathrm{CD}_{3} \mathrm{CN}, 25^{\circ} \mathrm{C}, 400 \mathrm{MHz}\right)$. Full spectra and peak assignment are shown in Fig. S14-S20 (ESI†).

HPLC analysis of reaction mixtures obtained after using $\mathrm{KMnO}_{4}$ showed the presence of one main degradant with a retention time of approximately $10 \mathrm{~min}$ (Fig. S3, ESI $\dagger$ ). LC-MS analysis identified this species as the endo-iminium impurity $\left(3,{ }^{22} \mathrm{~m} / \mathrm{z} 319.9\right.$, Scheme 1). Furthermore, formation of traces of the free Clp acid (1, $\mathrm{m} / \mathrm{z}$ 308.0), its iminium form $(\mathrm{m} / \mathrm{z} 306.0)$, and degradants containing pyridine fragments $(\mathrm{m} / \mathrm{z} 318.0,2$; $334.0,4)$ became evident. Notably, no decarboxylation of Clp to produce ticlopidine-type structures (Table S2, ESI $\dagger)^{8}$ was observed, most likely due to the absence of an aqueous medium. Furthermore, $\mathrm{C}-\mathrm{N}$ cleavage to produce thienopyridines, as it was described before using $\mathrm{KMnO}_{4}$ in solution, was not found. ${ }^{23}$ Formation of compound 3 as the main product could also be confirmed by ${ }^{1} \mathrm{H}$ NMR spectroscopic analysis (Fig. $3 \mathrm{~b}$ and Fig. S17, ESI $\dagger$ ). ATR-IR spectra (Fig. 4) show bands at $\nu 1650$ and $1580 \mathrm{~cm}^{-1}$ which can be assigned to $\mathrm{C}=\mathrm{N}$ bonds present in $\mathbf{3}$ and to pyridine containing fragments such as in $\mathbf{4}$, respectively.

With $\mathrm{KNO}_{3}$ the same main degradant was observed by HPLC analysis (Fig. S2, ESI $\dagger$ ) and identified as the endo-iminium compound 3, which explains the intense yellow colour of the reaction mixture (Fig. 2, right). UV analysis of the main HPLC signal at 11.4 min reveals absorption maxima at $\lambda_{\max }=216$, $306 \mathrm{~nm}$ (Fig. S5 and S6, ESI $\dagger$ ), values that are similar to those

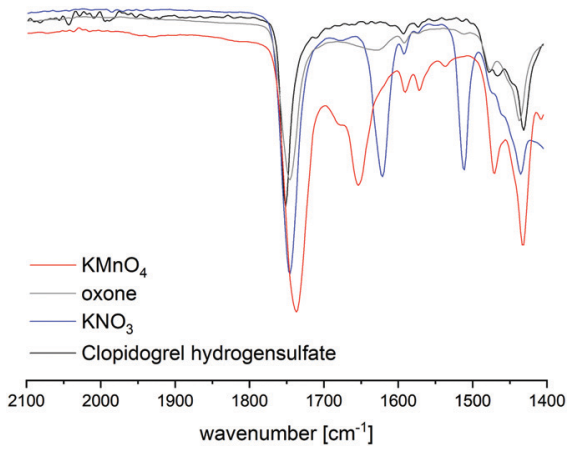

Fig. 4 Comparison of ATR IR spectra of Clp and reaction mixtures after ball milling in the presence of different oxidants after $t=15 \mathrm{~min}$. Shown is the spectral range that is characteristic for $\mathrm{C}=\mathrm{N}$ bonds. Full spectra are depicted in the ESI.†

reported already for compound $3 .^{22 a}$ Formation of this species occurs with greater selectivity compared to reactions that used $\mathrm{KMnO}_{4}$ as the oxidant. The formation of compound 3 was further corroborated using ${ }^{1} \mathrm{H}$ and ${ }^{13} \mathrm{C}$ NMR spectroscopic analysis of the reaction mixture in $\mathrm{CD}_{3} \mathrm{CN}$, which showed characteristic singlet resonances at $\delta \quad 6.48 / 9.06 \mathrm{ppm}$ $(\mathrm{CHCOOMe} / \mathrm{CH}=\mathrm{N})$, and $163.1 \mathrm{ppm}(\mathrm{CH}=\mathrm{N}),{ }^{22}$ respectively (Fig. 3c and Fig. S14-S16, ESI $\dagger$ ). In addition, several minor products could be detected, out of which an $\mathrm{N}$-oxide species 5 could be identified by LC-MS ( $\mathrm{m} / \mathrm{z} 338.0$, Scheme 1). ATR-IR spectroscopy shows similar pattern as for reactions with $\mathrm{KMnO}_{4}$, albeit with the above-mentioned bands being more resolved (Fig. S12, ESI $\dagger$ and Fig. 4).

A different degradation profile was found when Oxone ${ }^{\circledR}$ was used as the oxidant (Scheme 1). According to HPLC (Fig. S4, ESI $\dagger$ ), formation of compound 3 occurs in comparably small amounts, resulting in off-white reaction mixtures (Fig. 2, right). Instead, apart from several minor degradants, a main species with a retention time of approximately 17 minutes could be identified as the $N$-oxide 5 by LC-MS $(m / z$ 338.0). Selective transformation of Clp into this compound was achieved recently by application of oxone ${ }^{\circledR}$ in aqueous/organic solution. ${ }^{24}{ }^{1} \mathrm{H}$ NMR spectroscopic data of our mixtures are well
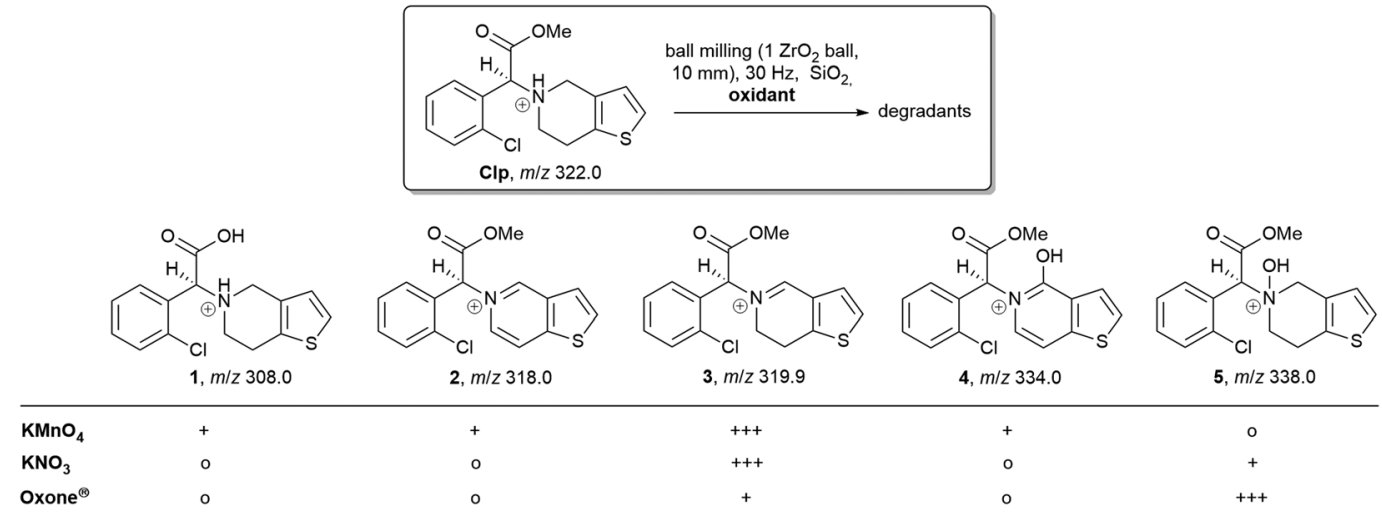

3, $m / z 319.9$

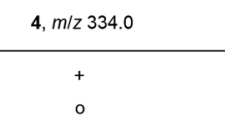

$5, m / z 338.0$

Scheme 1 Overview of main reaction products detected by LC-MS $(+++$ main product, + product was detected, o no formation of this product). For compound $\mathbf{4}$ only the literature-reported tautomer ${ }^{8}$ is shown. 
in line with those reported before, showing characteristic signals for both diastereomers of 5 (e.g. $\delta 6.84,6.80 \mathrm{ppm}, \mathrm{d}$, ${ }^{3} J=5.2 \mathrm{~Hz}$; Fig. 3d and Fig. S18-S20, ESI $\dagger$ ). In agreement with HPLC data, ATR-IR spectra show the above-mentioned bands at $1680 \mathrm{~cm}^{-1}$ that correspond to the $\mathrm{C}=\mathrm{N}$ bond in compound 3 (Fig. 4). Selective formation of clopidogrel $N$-oxide 5 by solidstate degradation has not been observed so far. Formation of $\mathrm{N}$-oxidised degradants of Clp was described before, ${ }^{6}$ however, in this case also hydrolysis of the ester group was evident. Mechanochemical oxidation of thiophene moieties, also using oxone $^{\circledR}$ was observed before. ${ }^{25}$ Analogous reaction products could not be found in any of our reactions.

Several publications deal with oxidative degradation products of Clp where several relevant structures were identified (Table S2, ESI $\dagger$ ). These studies were mainly performed in aqueous environment and required harsh conditions with high concentration of $\mathrm{H}_{2} \mathrm{O}_{2}$, high temperature and/or long reaction times. Interestingly, Singh and co-workers reported oxidation even with ambient oxygen, although very long reaction times of up to 3 months under elevated temperature were needed. ${ }^{8}$ However, also concurrent hydrolytic reactions were observed as the reactions took place in open vials at $40{ }^{\circ} \mathrm{C} / 75 \%$ relative humidity yielding corresponding acid analogues of oxidised Clp. Such degradants will not likely occur in solid-state APIs and formulations due to the low availability and mobility of water and slow reaction kinetics of hydrolytic cleavage, whereas the hydrolytic pathway seems to be preferred in water-based solutions as described in literature. ${ }^{8}$ Overall, the published artificial degradation profiles tend to be rather complex.

In contrast, our study shows high specificity and efficiency of mechanochemical formation of oxidative products of Clp, the obtained degradation product is clearly depending on the oxidant applied. The reaction was highly efficient and produced meaningful degradation profiles that may be used for the prediction of API stability under realistic conditions already after 15 minutes. Additionally, side reactions such as hydrolysis can be neglected as all oxidants delivered mainly oxidised ester products.

We thank Benjamin Andres, Andreas Koch, Susanne Schareina, Dr Henrik Lund and Dr Marcus Klahn for assistance. Financial support by the Leibniz-Gemeinschaft through the project PHARMSAF (K136/2018) is gratefully acknowledged.

\section{Conflicts of interest}

There are no conflicts to declare.

\section{Notes and references}

1 (a) K. C. Waterman and R. C. Adami, Int. J. Pharm., 2005, 293, 101-125; (b) M. Blessy, R. D. Patel, P. N. Prajapati and Y. K. Agrawal, J. Pharm. Anal., 2014, 4, 159-165.

2 P. J. Sharis, C. P. Cannon and J. Loscalzo, Ann. Intern. Med., 1998, 129, 394-405.

3 Clopidogrel hydrogensulfate, Monograph 2531 (01/2017), European Pharmacopoeia 10.0, EDQM Strasbourg, 2020.
4 Further salt forms of clopidogrel described in Ph. Eur. are clopidogrel besilate and clopidogrel hydrochloride.

5 P. R. Deshmukh, V. L. Gaikwad, P. K. Tamane, K. R. Mahadik and R. N. Purohit, J. Pharm. Biomed. Anal., 2019, 165, 346-356.

6 U. C. Mashelkar and S. D. Renapurkar, Int. J. ChemTech Res., 2010, 2, 822-829.

7 ICH: International Council for Harmonisation of Technical Requirements for Registration of Pharmaceuticals for Human Use.

8 K. Raijada, B. Prasad, A. Paudel, R. P. Shah and S. Singh, J. Pharm. Biomed. Anal., 2010, 52, 332-344.

9 S. L. James, C. J. Adams, C. Bolm, D. Braga, P. Collier, T. Friščić, F. Grepioni, K. D. M. Harris, G. Hyett, W. Jones, A. Krebs, J. Mack, L. Maini, A. G. Orpen, I. P. Parkin, W. C. Shearouse, J. W. Steed and D. C. Waddell, Chem. Soc. Rev., 2012, 41, 413-447.

10 (a) J. G. Hernández and C. Bolm, J. Org. Chem., 2017, 82, 4007-4019; (b) J.-L. Do and T. Friščić, ACS Cent. Sci., 2017, 3, 13-19; (c) T. Frisčic, C. Mottillo and H. M. Titi, Angew. Chem., Int. Ed., 2020, 59, 1018-1029; (d) I. N. Egorov, S. Santra, D. S. Kopchuk, I. S. Kovalev, G. V. Zyryanov, A. Majee, B. C. Ranu, V. L. Rusinov and O. N. Chupakhin, Green Chem., 2020, 22, 302-315; (e) J. L. Howard, Q. Cao and D. L. Browne, Chem. Sci., 2018, 9, 3080-3094.

11 (a) S. Hasa and W. Jones, Adv. Drug Delivery Rev., 2017, 117, 147-161; (b) M. Pérez-Venegas and E. Juaristi, ACS Sustainable Chem. Eng., 2020, 8, 8881-8893.

12 (a) D. Tan, L. Loots and T. Frisčic, Chem. Commun., 2016, 52, 7760-7781; (b) E. Colacino, A. Porcheddu, C. Charnay and F. Delogu, React. Chem. Eng., 2019, 4, 1179-1188; (c) P. Ying, J. Yu and W. Su, Adv. Synth. Catal., 2021, 363, 1246-1271.

13 L. Casali, L. Mazzei, O. Shemchuk, L. Sharma, K. Honer, F. Grepioni, S. Ciurli, D. Braga and J. Baltrusaitis, ACS Sustainable Chem. Eng., 2019, 7, 2852-2859.

14 (a) G. N. Herrmann, M. T. Unruh, S.-H. Jung, M. Krings and C. Bolm, Angew. Chem., Int. Ed., 2018, 57, 10723-10727; (b) A. Porcheddu, E. Colacino, L. De Luca and F. Delogu, ACS Catal., 2020, 10, 8344-8394.

15 S. Mateti, M. Mathesh, Z. Liu, T. Tao, T. Ramireddy, A. M. Glushenkov, W. Yang and Y. I. Chen, Chem. Commun., 2021, 57, 1080-1092.

16 (a) T. Stolar, S. Lukin, M. Tireli, I. Sović, B. Karadeniz, I. Kereković, G. Matijašić, M. Gretić, Z. Katančić, I. Dejanović, M. d. Michiel, I. Halasz and K. Užarević, ACS Sustainable Chem. Eng., 2019, 7, 7102-7110; $(b)$ C. Medina, D. Daurio, K. Nagapudi and F. AlvarezNunez, J. Pharm. Sci., 2010, 99, 1693-1696.

17 (a) F. Krauskopf, K.-N. Truong, K. Rissanen and C. Bolm, Org. Lett., 2021, 23, 2699-2703; (b) J.-H. Schöbel, P. Elbers, K.-N. Truong, K. Rissanen and C. Bolm, Adv. Synth. Catal., 2021, 363, 1322-1329; (c) K. J. Ardila-Fierro, S. Lukin, M. Etter, K. Užarević, I. Halasz, C. Bolm and J. G. Hernández, Angew. Chem., Int. Ed., 2020, 59, 13458-13462.

18 (a) H. H. Buschmann and N. Handler, WIPO (PCT) world patent, WO2018/096066 A1, 2018; (b) J. Urlaub, R. P. Kaiser, O. ScherfClavel, C. Bolm and U. Holzgrabe, Electrophoresis, 2021, 42, 1790-1799.

19 V. Koradia, G. Chawla and A. K. Bansal, Acta Pharm., 2004, 54, 193-204.

20 It is not possible to make a general statement about the polymorphic form in market products because there are many generic products, and some conversion can occur during the manufacture and formulation of the products.

21 For details of the MS analysis see the ESI $\dagger$ (Fig. S7-S12).

22 (a) A. Mohan, M. Hariharan, E. Vikraman, G. Subbaiah, B. R. Venkataraman and D. Saravanan, J. Pharm. Biomed. Anal., 2008, 47, 183-189; (b) Y. Zhu and J. Zhou, ACS Med. Chem. Lett., 2012, 3, 844-849.

23 K. S. Byadagi, R. V. Hosahalli, S. T. Nandibewoor and S. A. Chimatadar, Ind. Eng. Chem. Res., 2011, 50, 10962-10971.

24 E. F. Krake, H. Jiao and W. Baumann, J. Mol. Struct., 2022, 1247, 131309.

25 (a) G. Cravotto, D. Garella, D. Carnaroglio, E. C. Gaudino and O. Rosati, Chem. Commun., 2012, 48, 11632-11634; (b) B. Verbelen, E. Siemes, A. Ehnbom, C. Räuber, K. Rissanen, D. Wöll and C. Bolm, Org. Lett., 2019, 21, 4293-4297. 